\title{
On predictive entrepreneurial action in uncertain, ill-structured conditions
}

\author{
David J. Rapp ${ }^{1,2}$ (D) Michael Olbrich ${ }^{3}$
}

Received: 26 May 2020 / Accepted: 19 August 2020 / Published online: 3 September 2020

(C) The Author(s) 2020

\begin{abstract}
Decision-making is at the heart of entrepreneurship. Unsurprisingly, entrepreneurship research has engaged with processes of entrepreneurial decision-making resulting, most importantly, in the notions of causation, effectuation, and enactment. Nevertheless, the range of processes delineated to date remains somewhat incomplete. Drawing on crucial insights from the analysis of decision problem structures reveals that entrepreneurship theory has lacked a process that both recognizes the ill-structuredness typically surrounding entrepreneurial decisions and places prognoses center stage. While effectuation implicitly addresses structural defects but denies prognoses a central role, causation emphasizes the importance of predictions while being associated with well-structured, risky environments, and thus, unaffected by structural defects. Theorizing about a combination thereof, that is, a process recognizing and considering the ill-structuredness of entrepreneurial environments yet building on predictions of the future is overdue. This paper, therefore, seeks to foster a more comprehensive yet nuanced understanding of entrepreneurial decision-making processes by outlining the intrinsic features of one such process that we term execution and relating it to existing processes.
\end{abstract}

Keywords Causation · Effectuation · Enactment · Uncertainty · Ill-structuredness · Execution

JEL Classification D81 · L26

Mathematics Subject Classification 90B50 - 91B06

Michael Olbrich

olbrich@iwp.uni-saarland.de

David J. Rapp

david.rapp@imt-bs.eu

1 Law, Economics, and Finance Department, Institut Mines-Télécom Business School, Evry, France

2 Research Lab LITEM, Université Paris-Saclay, Univ. Evry, IMT-BS, Evry, France

3 Institute of Auditing, Saarland University, Saarbrücken, Germany 


\section{Introduction}

"Entrepreneurship is increasingly considered a milestone on the road towards progress" (Ribeiro-Soriano and Kraus 2018 referencing Semrau et al. 2016); unsurprisingly, therefore, entrepreneurship continues to attract considerable attention (Ferreira et al. 2019). Among the various streams of entrepreneurship research (Ferreira et al. 2019), one definition condenses the concept down to, "reasoned action in uncertainty" (Packard et al. 2017: 841). As action presupposes some kind of decision to act one way or another (including non-action), entrepreneurship research has placed the study of entrepreneurial decision-making in the face of uncertainty at its core (Shepherd et al. 2015). Research has inter alia centered on particular decisionmaking processes available to entrepreneurs, such as causation, effectuation, and enactment (Bhowmick 2015; Chandler et al. 2011; Read et al. 2009; Sarasvathy 2001, 2008). In addition - and somewhat related to the discussion on the various processes entrepreneurs (can) employ - a vigorous debate on the potential value of planning (Shane and Delmar 2004), specifically in new venture creation (Chwolka and Raith 2012; Gruber 2007), has ensued.

While the outlined paths of recent scholarship have spurred considerable progress in entrepreneurship research, theorizing on entrepreneurial decision-making processes remains somewhat incomplete. Drawing upon the well-established concept of decision problem structures which have long been known to exert a strong causal impact on the process utilized by decision-makers, this paper identifies a gap in the range of processes comprising causation, effectuation, and enactment. Causation, which largely builds on the idea of predicting the future, has been associated with well-structured decisions taken under risk and, as such, as being unsuitable for entrepreneurial decisions taken under Knightian uncertainty (Knight 1921). In contrast, effectuation (Sarasvathy 2001) has been developed as causation's opposite number, taking into account the uncertainty and ill-structuredness entrepreneurs usually face while restricting the use of predictions only to situations where they are unavoidable. Enactment to some extent resembles both causation and effectuation: Similarly to effectuation, enactment too supposedly gets along without predictions, putting initial action before sensemaking, which takes place only ex post. In a manner comparable to causation, enactment sidesteps the issue of ill-structuredness, albeit for different reasons.

However, to date the discussion has not encompassed a process that recognizes the uncertain, ill-structured decision environment yet still realizes how prognoses may be necessary, that is, a process offering a middle ground between causation and effectuation. Consequently, this paper encourages a broader, more nuanced picture of processes supporting entrepreneurial decision-making by outlining a notion of predictive entrepreneurial decision-making under Knightian uncertainty and illstructuredness more broadly: We term that process execution.

Responding to a call from Shepherd et al. (2015) and in line with Packard et al. (2017), the paper takes a processual perspective characterizing entrepreneurial decisionmaking in terms of a revolving process and, thus, in terms of a period of time including recursive judgment rather than in terms of a single decision at a particular point in time. 


\section{The structure of decision problems and entrepreneurial decision-making processes}

\subsection{Structure of decision problems}

Entrepreneurial decisions are multifarious. They range from starting a new venture (e.g., Forlani and Mullins 2000) to exiting an established one (e.g., DeTienne et al. 2015), spanning the entire life cycle of a particular venture and beyond, and including decisions about financing (e.g., de Bettignies and Brander 2007), product innovation (e.g., Dougherty and Heller 1994), and the timing and mechanism of market entry (e.g., Lévesque and Shepherd 2004).

Normative decision theory delineates characteristics required of decision problems to allow for a so-called rational choice (Arrow 1951a, b; Hansson 1994; Langlois 1982; Sarasvathy 2001; Simon and Newell 1958; Wilson and Alexis 1962). In short, those problems must be "well structured" (Simon and Newell 1958: 4). Wellstructuredness is present whenever the underlying decision problem "can be formulated explicitly and quantitatively, and [...] then be solved by known and feasible computational techniques" (Simon and Newell 1958: 5). The decision-maker must know what options are available, what are the potential outcomes of those options, how they can be appraised, and how the decision problem can be solved bearing in mind the well-specified goal(s) of the decision-maker. Those prerequisites place a decision-maker in the position to choose the optimal solution to a problem and, thus, to make a so-called rational choice (Ariely 2009; Kahneman and Tversky 1979; Miller 2007; von Neumann and Morgenstern 1944; Savage 1954; Simon 1976).

Typical entrepreneurial decisions, however, are far from being well-structured; quite the contrary in fact. Entrepreneurs (may) face decision problems afflicted with various structural defects causing them to perceive decision environments as ill-structured rather than well-structured (Adam and Witte 1979; Newell 1969; Reitman 1964; Simon 1973; Simon and Newell 1958). Ill-structuredness occurs whenever decision problems fail to correspond to the entire range of characteristics outlined above. In other words: "Problems are ill-structured when they are not well-structured" (Simon and Newell 1958: 5).

The gamut of structural defects potentially causing ill-structuredness encompasses:

1. Unspecified or conflicting goals (see, for instance, the discussion of "a multiobjective theory of the firm" by Pies et al. (2019)) (prompting a goal defect; as for instance, if an entrepreneur has in mind a particular idea for a venture yet has a strong inclination toward safety that conflicts with making the investments required to transform the idea into action),

2. Limited knowledge about future outcomes of current action (prompting a causality defect; for instance, whenever an entrepreneur launches a new product, whether consumers will appreciate and purchase the product is highly uncertain. In other words, the future effects of current action are not well-known in advance), 
3. The inability to appraise different options to act (prompting an appraisement defect; as when the aspired-to effects of an action are not easily quantifiable; for instance, if an entrepreneur makes a strategic decision on whether or not to enter a new line of business), and

4. Failure to computationally solve the decision problem at hand (prompting a solvability defect; for instance, if an entrepreneur faces particular forms of sequence problems, such as processing incoming orders or deciding on the route for delivery services) (Adam and Witte 1979; Wilson and Alexis 1962; Witte 1979).

Given that research addressing entrepreneurship mostly interprets uncertainty in terms of options available to the entrepreneur and possible outcomes of those options (Foss and Klein 2012; Milliken 1987; Packard et al. 2017; Townsend et al. 2018), it is evident that uncertainty thus defined largely matches one particular facet of ill-structuredness, namely the causality defect.

Ill-structuredness of various kinds prohibits entrepreneurs from making optimal decisions; instead they are constrained to seeking a satisficing (Simon 1976) solution to the initial problem (Beckert and Bronk 2018; Gigerenzer 2008; Wilson and Alexis 1962).

\subsection{Entrepreneurial decision-making processes: causation, effectuation, and enactment}

\subsubsection{Process features}

Causation, effectuation, and enactment and its derivatives (see, for instance, Welter et al. 2016 on the interrelations between effectuation and creation and bricolage theories) have been among the processes discussed most often in the context of entrepreneurial decision-making. Therefore, we will concentrate on these three processes and investigate them in light of our framework of decision problem structures. To do so, it is necessary to first outline their respective features and to delineate them from one another, at least analytically, even though they might co-occur, intertwine, and overlap in actual human reasoning (Bhowmick 2015; Sarasvathy 2001).

In her seminal paper, Sarasvathy (2001) introduces a theory of effectuation and contrasts this decision-making process with its counterpart causation. Fundamentally, she distinguishes between the two based on the underlying logic of each of the processes. While she associates causation with prediction, she emphasizes the role of control in effectuation. Causation is linked to well-structured decision problems (Sarasvathy 2001) and, in short, rests on the idea that entrepreneurs choose "optimal" paths of action in the present which are believed to maximize possible future returns as predicted by the entrepreneur. The entrepreneur is hence aware of the desired end and selects the alternative from the option set that he or she believes will deliver that end best possible.

Effectuation has been argued to take the opposite stance (Bhowmick 2011; Dew et al. 2008; Dew and Sarasvathy 2002; Grégoire and Cherchem 2020; Read and 
Sarasvathy 2005; Schneider 2018; Tumidei et al. 2020) and has been juxtaposed with causation in different respects (Dew et al. 2009; Fisher 2012; Read and Sarasvathy 2005; Shirokova et al. 2020). Effectuation describes a process apt for facing an environment which is uncertain and ill-structured to a degree that does not make it possible to predict the future; alternatively, effectuation leans on the idea that to "the extent that we can control the future, we do not need to predict it" (Sarasvathy 2001: 252). Therefore, effectuation processes take a limited set of means as given (rather than the aspired effect as in causation processes) and-predetermining a particular level of affordable loss-focus on the various effects which can be created through control of the available means while making use of strategic alliances and exploiting contingencies over time. Therefore, the "distinguishing characteristic between causation and effectuation is in the set of choices: choosing between means to create a particular effect, versus choosing between many possible effects using a particular set of means. Whereas causation models consist of many-to-one mappings, effectuation models involve one-to-many mappings" (Sarasvathy 2001: 245). The concept of bricolage, first elucidated by Lévi-Strauss (1967)—and first applied to the field of entrepreneurship by Baker and Nelson (2005)—while differing in detail, largely resembles the notion of effectuation. It does so in particular because of its central tenet of "making do with what is at hand" (Baker and Nelson 2005: 329). Accordingly, it too starts from consideration of the constrained resources available to the entrepreneur. Given the strong ties between both bricolage and effectuation (Fisher 2012), we focus the following discussion expressly on effectuation; however, the findings derived are not limited to effectuation per se but apply similarly to related approaches too.

Enactment, which borrows from Weick's sensemaking conception (Weick 1979, 1995; Weick et al. 2005), essentially describes the idea of non-directed action that is made sense of only after it took place (Bhowmick 2015). Therefore, enactment in some sense resembles effectuation and contrasts with causation (Sarasvathy 2001). Both effectuation and enactment rest on the premise that the dynamic environment is too uncertain to be predicted and, hence, does not fall into the scope of causal reasoning with its optimization analyses. Both effectuation and enactment emphasize the constructive feature of eventual outcomes rather than the predictive feature. Consequently, Bhowmick (2015: 519) states: "In a fundamental way, both concepts give primacy to action over pre-planning in explicating organizing and exploring."

While enactment and effectuation are similar in some respects, they are also distinct from each other, in particular with regard to the directedness of action (Bhowmick 2015). While the enactment concept puts non-directed action before sensemaking, the effectuation logic implies that entrepreneurial action targets control. Moreover, the given set of means is central to the effectuation logic, while enactment gets along without explicit reference to particular means, thus leading Bhowmick (2015) to refer to effectuation as resource-dependent action and to enactment as resource-independent action.

In sum, both effectuation and enactment are designed to match uncertain conditions and preclude the making of meaningful predictions, whereas causation considers well-structured environments under risk and largely builds on predictions of future states of affairs. Figure 1 illustrates the inchoate range of processes that leaves 


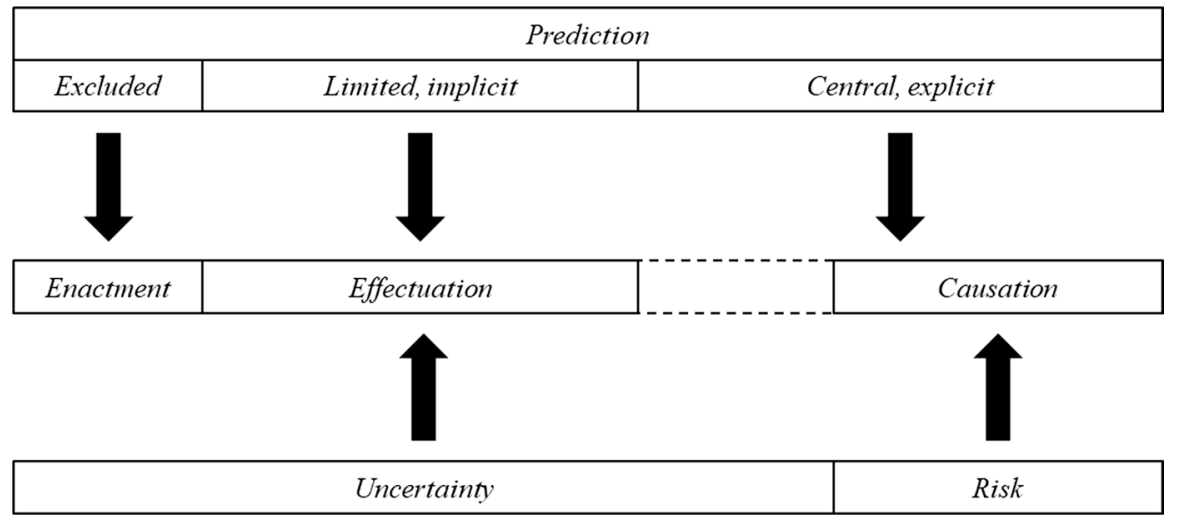

Fig. 1 Decision processes in light of both the degree of unknowingness and their stance on predictions

room for a process of entrepreneurial decision-making capable of both incorporating uncertainty and building on prognoses.

\subsubsection{Recognition of structural defects}

Bhowmick (2015: 528) has argued that "under uncertainty, entrepreneurial actions have a non-causation basis" and thus classes causation as a tool for entrepreneurial action under risk rather than uncertainty. Similarly, causation has been directly linked to well-structured, risky decision problems (Sarasvathy 2001). We follow both Sarasvathy (2001) and Bhowmick (2015) in their classification of causation, and, thus, deviate from Packard et al. (2017) in this respect who characterize causal approaches as a means of transforming absolute uncertainty into creative uncertainty aiming to arrive at a manageable decision problem.

If causation falls into the scope of well-structured decision problems, then structural defects are meaningless and can neither be recognized nor addressed. Unlike causation, neither effectuation nor enactment have been subject to an investigation of whether the concepts recognize structural defects with which the decision problem they are designed to solve may be afflicted and, if so, how they try to address them. This is surprising, given that both effectuation and enactment are two ways of dealing with uncertain, and hence ill-structured, decision problems.

Effectuation rests on the idea that entrepreneurs start with a given set of means, particularly with who the entrepreneur is, what he or she knows, and whom he or she knows (Sarasvathy 2001, 2008). The entrepreneur then imagines potential effects that can be created with the available means and eventually selects one of those effects in light of his or her (contingent) aspirations based on what he or she considers an affordable amount of loss.

Effectuation implicitly recognizes at least three structural defects and incorporates particular ways of addressing them: First, the effectuator lacks a consistent goal to be targeted and hence suffers from a goal defect. Effectuation proposes the entrepreneur refers to general, contingent, and, thus, vague human aspirations 


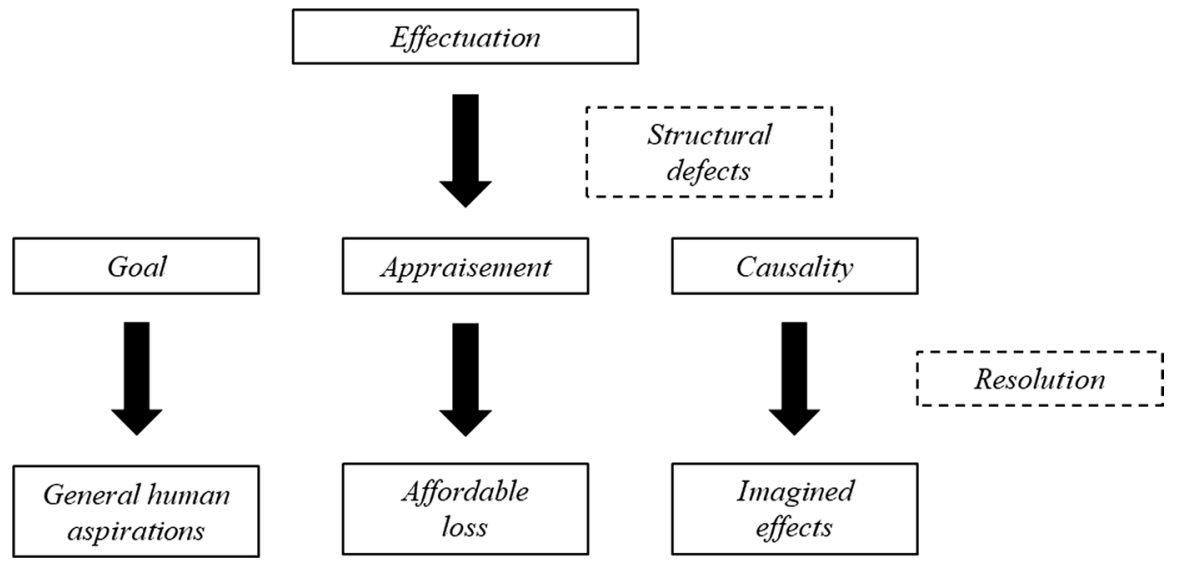

Fig. 2 Structural defects recognized in effectuation and attempts at resolution

as its reply to this dilemma. Second, the effectuator is quite unaware of how to appraise different imagined effects and consequently suffers from an appraisement defect. Effectuation, again, provisionally suggests a quite general and vague criterion for the appraisement and selection of one particular effect, namely affordable loss as its attempt to resolve the ill-structuredness. Third, while the entrepreneur's set of means is taken for granted, the particular outcomes of available options are uncertain. Therefore, the effectuator is confronted with a causality defect. The "solution" to this issue as implied in effectuation is to imagine possible effects that can be created with the set of means and, therefore, to artificially close the initially open set of outcomes. Figure 2 illustrates effectuation's relation to structural defects and its attempts to resolve them.

In sum, effectuation indeed implicitly recognizes various structural defects and, hence, the ill-structuredness of the decision problem it is designed to deal with and includes different ways to resolve the various defects. Therefore, effectuation can be understood as a means of partly reducing the perceived degree of ill-structuredness and, eventually, of arriving at a manageable decision problem through a particular degree of pre-structuring.

Like effectuation, enactment too is a process of entrepreneurial decision-making in the face of uncertainty and, hence, ill-structuredness. Unlike effectuation, however, enactment does not include any pre-structuring of the decision problem and instead emphasizes the initial non-directed action and the sensemaking of what was done only ex post. Therefore, even though decision problems suitable for enactment are afflicted with structural defects, enactment itself remains silent on them and, thus, does not address them. Rather than addressing the ill-structuredness, enactment simply bypasses its implications through action preceding thought (Weick 1979, 1995). 


\subsubsection{What does the problem structure reveal about the range of possible decision-making processes?}

As outlined above, decision problems may either be well-structured or ill-structured, the latter to different degrees, depending on both the amount and magnitude of structural defects associated with the ill-structuredness. To this point we have discussed three existing decision-making processes and related them to either well-structuredness or ill-structuredness, respectively. We distinguished each of these processes based on whether or not it recognizes structural defects.

Moreover, they can be differentiated according to the role of prognoses in the processes. While effectuation at least implicitly recognizes various structural defects, it denies prognoses a key role. Enactment, in contrast, skips recognizing and addressing structural defects while similar to effectuation, prognoses are not central to the process either. Even though it is indeed true that both effectuation and enactment reject the logic of prediction on a fundamental level, the degree to which they do so varies. While it can be argued that every action is aimed at improving the state of affairs (von Mises 1949) and, hence, implies an expectation and, thus, a prediction of how the action can improve this state, enactment in some sense largely gets along without any reference to explicit prediction putting action before sensemaking.

Effectuation, however, while emphasizing the logic of control and differentiating itself from causation through rejecting the logic of prediction, still requires a certain degree of prediction and planning. It is, for instance, necessary when trying to imagine effects possibly creatable with the given means or when deciding on the level of affordable loss. That is because a particular loss can only be affordable in light of other obligations the effectuator faces in the future. Sarasvathy (2001: 260, emphasis added) seems to acknowledge the fact that the process she suggests requires some planning when she states, "effectuation does not involve elaborate planning."

Causation bypasses structural defects simply because it is designed to deal with decision problems in well-structured situations where there are none, while relying heavily on prognoses which are key to causation.

Analyzing the range of existing decision-making processes in light of both the potential recognition of structural defects and the role they give to prognoses reveals that the range is incomplete. It lacks a process which recognizes the ill-structuredness of the decision problems entrepreneurs usually face yet puts prognoses center stage. Therefore, this paper outlines a process incorporating these attributes that we term execution. Table 1 summarizes the positioning of effectuation, enactment, causation, and execution with regard to the recognition of structural defects and the role of prognoses.

\section{An outline of execution as a process of entrepreneurial decision-making}

\subsection{Process features}

Apart from strengthening the awareness among entrepreneurship scholars of the concept of ill-structuredness and its usefulness for theorizing about entrepreneurial 
Table 1 The role of structural defects and prognosis in decision-making processes

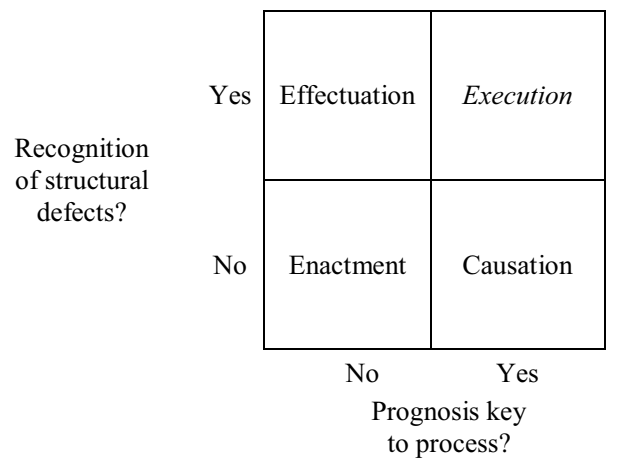

decision-making in general, this paper also seeks to outline foundational elements of execution as a means of decision-making in uncertain, ill-structured situations.

The Cambridge Dictionary offers one definition of execution as, "the act of doing or performing something, especially in a planned way." Similarly, the Oxford Dictionary paraphrases execution as the "carrying out of a plan, order, or course of action." Applied to our specific context of entrepreneurial decision-making in ill-structured decision situations, we define our execution tenet as: a dynamic and recursive process of planning by means of pre-structuring a decision problem perceived as ill-structured, through subjectively resolving identified structural defects and applying judgment to decide and act upon the decision problem once its structure has been sufficiently improved.

Hence, execution shares features of both causation and effectuation. ${ }^{1}$ While it rests on the logic of prediction, it recognizes the entire range of structural defects and, consequently, rejects simple extrapolations and attempts at optimization analyses. In some sense, it can be referred to as causation's pendant under uncertainty, integrating the missing piece of ill-structuredness and the implications flowing from it into the decision-making process. The central question is: How would such integration look?

Execution requires the perception of decision problems as ill-structured from the outset; hence, execution cannot aim to deliver optimal decision-making but offers a route to satisficing (Simon 1976) solutions to decision problems. If a decision environment is perceived as ill-structured, it suffers from at least one (but likely several) structural defect(s) (Adam and Witte 1979; Wilson and Alexis 1962; Witte 1979). Dealing with such situations via execution rests on the idea of heuristically addressing and resolving the identified structural defects and combining the resulting partial solutions to eventually reach a practicable overall solution (Adam 1983).

\footnotetext{
${ }^{1}$ In contrast to effectuation, which has directly been linked to new venture creation in particular (Sarasvathy 2001), execution is wider in scope: It is applicable to entrepreneurial decision-making in both start-ups and well-established firms, including family firms (and, hence, the form of entrepreneurship primarily studied in Review of Managerial Science, see Mas-Tur et al. 2020).
} 
If an entrepreneur is faced by competing ends, for instance, resolving such a goal defect may be achieved by specifying the extent of each of the targeted ends, for example, a particular minimum number of jobs to be created or a minimum level of liquidity available. Not knowing the entire range of both options to act and their possible outcomes, that is, facing a causality defect, may be addressed by means of imagining and, as such, subjectively populating both the option and outcome sets (Packard et al. 2017) and excluding scenarios conflicting with the intended goals. Dealing with identified structural defects in such a way is a helpful means to prestructure the problem and reduce its overall complexity. Which path of action the entrepreneur eventually favors largely depends on the goals pursued and the entrepreneur's predictions of how the future will look.

Consider an entrepreneur who is eager to enter the fashion market: While bearing financial ends in mind, she also seeks to manufacture her fashion wear in an environmentally friendly way and to do good by employing socially disadvantaged members of her local community. Simultaneously striving for those goals could create a goal conflict. Both considering environmental issues and employing members of the local community might increase costs compared to possible alternatives, such as, outsourcing production to South-East Asia. In other words, the entrepreneur's non-financial goals are likely to negatively impact the firm's financial outcomes. In order to resolve that goal conflict, the entrepreneur might pragmatically operationalize the desired non-financial goals and seek to attain the best possible financial outcome on condition the other two goals are met. For instance, the entrepreneur might consider the environmental objective to be met if the firm only uses organic fabrics and the social goal to be met if at least $50 \%$ of the firm's workforce meets the criteria of being both socially disadvantaged and from the entrepreneur's community.

Apart from the goal defect, our entrepreneur must also deal with a causality defect because she lacks complete insight into both potential options and their outcomes. The fashion entrepreneur will be confronted with many choices, including over fabrics, colors, cuts, styles, and sales channels, all of which come with unknown future effects. Our fashion entrepreneur might first discard options that clash with her goals; that might, for instance, entail rejecting all options based on non-organic fabrics or manufacturing in South-East Asia. The entrepreneur subjectively populates the sets of both options and outcomes by imagining possible paths of action and making educated guesses about the respective future state of affairs. A potential outcome for this particular entrepreneur could be to produce comfortable infant's clothing in natural tones made from organic cotton to be sold both online and in local children's clothing stores.

While execution thus understood will not be optimizing (which is out of reach under ill-structuredness anyway), it certainly both supports necessary entrepreneurial judgment and allows for a satisfying decision in uncertain, ill-structured conditions. Because entrepreneurial decision-making is not well captured in terms of one-time decisions but as dynamic and continuous processes instead (Packard et al. 2017; Shepherd et al. 2015; Wood et al. 2017), execution takes a largely processual form. The heuristic process of complexity reduction through pre-structuring an initially intractable problem may require several recursion loops (Adam 1996) before the initially ill-structured problem is perceived as somewhat better structured and, 
thus, pragmatically solvable. Once a decision has been taken and as time passes, new information arises demanding subsequent revisions of the initial action and, hence, subsequent judgment and action (Packard et al. 2017).

\subsection{Decision-making processes as a function of the problem structure}

\subsubsection{Fit with problem structure}

Objectivity is not a property of the structure of decision problems. While there are objective facts associated with each particular problem, there is no objective measure of whether or not it is ill-structured and, if so, to what degree. Characterizing a problem as ill-structured must necessarily result from an individual entrepreneur's personal perception. Because entrepreneurs differ in their subjective perceptions of the environment and the general circumstances relevant to their actions (Karhu and Ritala 2020; Shepherd et al. 2015), perceptions about the structure of a particular decision problem will necessarily differ from one entrepreneur to another. Hence, the selection of a decision-making process can only be suitable in light of a particular perception of the underlying problem (Beckert and Bronk 2018). Neither process is generally superior to its alternatives, but its usefulness depends on the circumstances the entrepreneur faces and interprets subjectively (Gigerenzer 2008; Gigerenzer and Gaissmaier 2011; Sarasvathy 2001).

Nevertheless, decision-making processes designed to deal with uncertainty and ill-structuredness respectively, namely effectuation, enactment, and execution, differ fundamentally from each other with regard to how they suit different perceived decision contexts. They can particularly be distinguished by the degree of specificity of certain decision parameters, namely end(s), means, and the selection criterion.

Execution is the most specified process among the three mentioned. It specifically recognizes the role of ends, means, and the selection criterion and incorporates them into the process. Effectuation does so to a lesser degree: While it relies heavily on the means available to the effectuator, both ends (in the form of general human aspirations) and the selection criterion (affordable loss however determined) are quite vague. Enactment requires decision parameters to be even less specified. There is no clear place for either ends or a selection criterion and even if means must play some role (as one has to employ some means to do something) there is no direct reference to the role of means, which is expressed quite well in Bhowmick's (2015) depiction of enactment as resource-independent action.

Table 2 provides an overview of the degree of specificity of the decision-making processes designed to address uncertain, ill-structured decision problems with regard to ends, means, and the selection criterion.

Execution, effectuation, and enactment are three different tools applicable to deal with ill-structured decision problems. Even though the answer to the question of which of these processes fits which particular decision best, only depends on the personal perception of the acting entrepreneur about the decision circumstances, in general, we can ascertain that the three processes constitute a range reflecting options suitable to deal with different degrees of ill-structuredness. We can tell that 
Table 2 Specificity of decision-making processes in ill-structured situations

Decision-making processes in ill-structured decision situations

\begin{tabular}{lllll} 
& & Execution & Effectuation & Enactment \\
\hline Recognition of... & ...ends & + & \pm & - \\
& ...means & + & + & \pm \\
& ....selection criterion & + & \pm & - \\
\hline
\end{tabular}

the more a problem is perceived as ill-structured and, as such, the more a problem is perceived as vague and unspecified, the more superior effectuation and enactment might be to execution (albeit slightly ill-structured problems that are perceived as risky rather than uncertain might be a good fit for effectuation, too, as argued by Welter and Kim (2017)).

The less the decision circumstances allow for a sufficient amount of planning through pre-structuring the ill-structured problem, the better effectuation and particularly enactment seem to fit. Accordingly, the range of possible processes generally goes from execution via effectuation to enactment with regard to the degree of ill-structuredness, vagueness, and lack of specificity of the underlying decision problem. However, focusing on the degree of detailed planning associated with each of the processes, the range goes from enactment via effectuation to execution and, hence, vice versa. It follows that less ill-structured, less vague, more specified problems allow for a more sophisticated planning and, hence, for the application of execution.

Figure 3 illustrates the range of possible decision-making processes in light of the degree of ill-structuredness, vagueness, and lack of specificity at one extreme and their inherent degree of detailed planning at the other.

\subsubsection{Temporality of the entrepreneurial journey}

Entrepreneurial decisions like that to enter or literally create a specific market with a particular (revolutionary) product, can barely be described in terms of isolated onetime decision problems that can be solved just once and permanently. Instead, judgmental entrepreneurial decision-making must be viewed as a continuous and recursive process (McMullen 2015; McMullen and Dimov 2013; Packard et al. 2017) and, as such, in terms of a period of time rather than a point in time.

The temporality of the entrepreneurial journey implies that entrepreneurs' perceptions of their circumstances alter as time passes. Corbett (2007) emphasizes the importance not only of what one knows, but also of how one processes new information. Such new information, and particularly that acquired through learning and experience (Mitchell and Shepherd 2012), will naturally make entrepreneurs change how they regard their decision environment (Knight 1921). While it has been argued that Bayesian learning is at odds with Knightian uncertainty and, thus, unsuited for situations regularly faced by entrepreneurs (Packard et al. 2017), its fundamental 
Degree of detailed planning

Execution

Effectuation

Enactment

\section{Degree of perceived ill-structuredness \\ Vagueness, lack of specificity}

Fig. 3 Perceived ill-structuredness and decision-making processes

idea of differing decision bases a priori and a posteriori respectively, can be transferred into the sphere of the entrepreneurial journey in a less formalized fashion.

We agree with Beckert and Bronk (2018) and Knight (1921) who argue that most decisions with regard to their degree of unknowingness are neither black nor white but various shades of gray. Hence, while the entrepreneur utilizes his or her specific knowledge (Wood and Williams 2014) about some things, other aspects are unknown and possibly unknowable. Therefore, entrepreneurs imagine potential future scenarios (Klein 2008) by drawing on their specific individual state of a priori knowledge. Once the initial decision has been taken (i.e., a posteriori), the foundation of the decision will be changed owing to the improved information base. Therefore, entrepreneurs might also subsequently reevaluate how they perceive the structure of a particular decision problem in their ongoing judgment and, consequently, the process they apply to that problem (similarly Jiang and Tornikoski 2019 who analyze the relation between perceived uncertainty and process selection).

Different directions can be imagined: It seems quite obvious that particularly when a product never seen before shall be launched, processes emphasizing the role of acting itself without much reference to structured pre-planning and prognoses can serve as a reasonable starting point, namely enactment and effectuation, which might even be applied complementarily (Bhowmick 2015). Effectuation has been directly linked to new ventures, new products, new markets (Sarasvathy 2001) and it therefore has a narrower field of application than execution. As time goes by, entrepreneurs learn and acquire experience that might impel them to switch from enactment or effectuation toward execution if they perceive the altered structure of the problem suitable.

However, even ventures that will create a new market are not limited to effectuation or enactment; but might instead be a good fit for execution. For instance, although Jeff Bezos was about to pioneer e-commerce with Amazon, he did so with structured financial planning and an emphasis on maximizing future return rather than with recourse to a certain amount of affordable loss (Stone 2013). Moreover, he was equipped with a range of quite specific goals rather than merely vague general human aspirations (Stone 2013). 
While learning and experience might cause entrepreneurs to switch from effectuation or enactment to execution in their subsequent judgment, the direction might run vice versa too. Research finds that entrepreneurs can be prone to overconfidence (Busenitz and Barney 1997; McKelvie et al. 2011; Shepherd et al. 2015; Townsend et al. 2010; Wu and Knott 2006; Zacharakis and Shepherd 2001) and one result of such overconfidence can be the application of execution to a problem unsuitable for the process. An inexperienced entrepreneur entering a market for the first time with a novel product, for example, might falsely — which she can learn only ex post-perceive the decision problem as ill-structured to a degree that allows pre-planning and predicting. However, if it turns out that the execution process was inappropriate, the entrepreneur might alter her ideas about applying effectuation or enactment, if the initial decision did not prove fatal to the business. Regardless, the selection of a process to be applied to entrepreneurial decision-making is related to the life cycle of a product and/or an entire firm.

If an entrepreneur is not eager to enter a market with an innovative product but seeks to imitate other competitive products, execution seems to be a good starting point given the history of other products and firms manufacturing them. In that case, the entrepreneur essentially does not have to learn and experience everything alone and can benefit from the observable actions of others (Rae and Carswell 2000).

Different decision-making processes can also certainly be used within the same firm simultaneously. For instance, if a particular business has offered a specific product in one market for decades and can therefore address pending decisions with execution, it might at the same time plan on penetrating a foreign market that has never seen a similar product. Given that the potential consumers in the foreign market might be quite different from the consumers in the domestic market, perhaps owing to fundamentally different cultural values and norms (Hofstede 1980; Steenkamp et al. 1999), it can be wise to start off with an enactment- or effectuation-based process rather than confidently applying experience acquired in the domestic market in a new foreign one.

\subsubsection{Entrepreneur? Which entrepreneur?}

The literature offers different concepts of who is an entrepreneur or who acts entrepreneurially and the range spans from very broad understandings of entrepreneurship to quite narrow ones (Klein 2008; Salerno 2008). It has been argued (justifiably in the authors' opinion) that most human action is in some sense entrepreneurial as it is undertaken in the face of uncertainty (Herbener 1992; von Mises 1949). At the other end of the scale, some literature prefers to very tightly define entrepreneurship as relating only to actions with reference to start-up firms (e.g., Kim 2015). Neither extreme is particularly useful for our discussion, and we therefore follow Klein (2008), Salerno (2008), and others in focusing on the middle ground between the two, incorporating far more than only start-up ventures while not considering any human action specifically entrepreneurial. 
Moreover, entrepreneurship has inter alia been discussed as an (at most) analytically distinct function ("pure entrepreneur") (Kirzner 1973) and based on a more practical approach characterizing entrepreneurs as having ownership of the means of production and, as such, being the ultimate decision-makers (Foss and Klein 2012; Klein and Klein 2001; Salerno 2008). The latter concept reveals that "the entrepreneur is nearly always also a capitalist, and the capitalist is also an entrepreneur" (Klein 1999: 21).

While execution can be the ideal decision-making process for any entrepreneur independent of the market she acts in while contingent on the actual decision she faces and her perception of the problem structure, it seems particularly suited for the specific cases of the financial-market entrepreneur (Klein 1999) or "financiers as entrepreneurs" (Klein 2008). Investors must not be misunderstood as mere passive funders of entrepreneurial ventures; rather, they are entrepreneurs themselves (Landström 1998), exercising judgment on the allocation of their scarce means among their investment opportunities, doing so under conditions of uncertainty, aiming to make profit. Scholars in the Austrian tradition such as von Mises (1949), Rothbard (1962), and Klein (1999) have even argued that the "capitalist-entrepreneur" plays the most important role in the market economy and can be viewed as the driving force behind it.

While there is no natural necessity for this particular class of entrepreneurs to make use of execution, this process tends to be the primary vehicle suitable to address investors' decision problems. In general, they would rather not build on processes that bypass sufficient pre-planning along with prognostic elements, which means that neither effectuation nor enactment naturally seem the best fit. That is also because investors usually act on their personal anticipation of future returns (Klein 1999), a feature that is missing in these processes. ${ }^{2}$ Therefore, even when particular entrepreneurs appear as effectuators or "enacters" creating their venture, execution might still play an important role in those ventures if the effectuators or "enacters" seek external financing by a financial-market entrepreneur. As Hsu (2004: 1805) points out, "convincing external resource providers such as venture capitalists to provide financial capital may be challenging" and to do so might actually be a function of how plausibly effectuators or "enacters" can communicate how they imagine their business will develop in the future. A mere reference to vaguely imagined effects-or in the words of Sarasvathy (2001: 262), "when destinations are unclear and there are no preexistent goals" - in case of effectuation or to the general and loose idea of action before sensemaking in enactment might be insufficient to convince the financial-market entrepreneur to invest. This, in fact, might have been the reason why Jeff Bezos deliberately worked out a business plan, including "typing revenue projections into an Excel spreadsheet" (Stone 2013: 29), before pitching his venture to potential investors (Stone 2013).

\footnotetext{
2 This is not to say, however, that investors abstain completely from applying effectual logics. Wiltbank et al. (2009), for instance, investigate differences among angel investors using predictive, causal logics versus those who opt for effectual logics.
} 


\section{Conclusion}

Judgmental decision-making is the very essence of entrepreneurship. We build on the notion of ill-structured decision problems being typical of the decisions facing entrepreneurs. The analysis reveals that the range of decision-making processes discussed so far comprising causation, effectuation, and enactment is somewhat incomplete. Therefore, we delineate fundamental features of a novel process that we term execution to fill the missing segment. Execution recognizes the potential ill-structuredness of problems, incorporates prognoses, and approaches the problem through pre-structuring it. The latter activity is completed by resolving the respective structural defects associated with it to allow for an improved problem structure and, eventually, a satisficing decision outcome when optimal solutions are simply unavailable.

Neither of the processes is generally better or worse than its counterparts; whether or not a particular process is more or less helpful only depends on the entrepreneur's personal perception of the structure of the decision problem. Each process generally fits specific circumstances better than the other processes and, hence, each has its particular field of application.

The entrepreneur's perception, however, cannot be static in a dynamic, everchanging environment. Therefore, we take a processual perspective in arguing that the temporality of the entrepreneurial journey necessitates changing perceptions as time goes by, resulting in altering selections of suitable decision-making processes in the entrepreneur's ongoing judgment. We suggest that focusing on ill-structuredness better links entrepreneurship research to valuable insights from decision theory, and hence provides a more comprehensive picture of entrepreneurial decision-making, which lays the ground for new directions in entrepreneurship research.

Acknowledgements We thank Professors Peter G. Klein and Matthew S. Wood for both their willingness to discuss the ideas outlined in previous versions of our paper and their provision of valuable comments. We, moreover, wish to sincerely thank both the responsible Associate Editor, Professor Sascha Kraus, and the two anonymous reviewers for their helpful remarks which allowed us to advance our paper further.

Funding This research did not receive any specific grant from funding agencies in the public, commercial, or not-for-profit sectors. Open Access funding provided by Projekt DEAL.

Availability of data and material Not applicable.

\section{Compliance with ethical standards}

Conflict of interest The authors declare that they have no conflict of interest.

Open Access This article is licensed under a Creative Commons Attribution 4.0 International License, which permits use, sharing, adaptation, distribution and reproduction in any medium or format, as long as you give appropriate credit to the original author(s) and the source, provide a link to the Creative Commons licence, and indicate if changes were made. The images or other third party material in this article are included in the article's Creative Commons licence, unless indicated otherwise in a credit line to the material. If material is not included in the article's Creative Commons licence and your intended use is not permitted by statutory regulation or exceeds the permitted use, you will need to obtain permission directly from the copyright holder. To view a copy of this licence, visit http://creativecommons.org/licen ses/by/4.0/. 


\section{References}

Adam D (1983) Planung in schlechtstrukturierten Entscheidungssituationen mit Hilfe heuristischer Vorgehensweisen. Betriebswirtschaftliche Forschung und Praxis 35:484-494

Adam D (1996) Planung und Entscheidung. Gabler, Wiesbaden

Adam D, Witte T (1979) Merkmale der Planung in gut- und schlechtstrukturierten Planungssituationen. Das Wirtschaftsstudium 8:380-386

Ariely E (2009) Predictably irrational: the hidden forces that shape our decisions. Harper Collins, New York

Arrow KJ (1951a) Alternative approaches to the theory of choice in risk-taking situations. Econometrica 19:404-437

Arrow KJ (1951b) Social choice and individual values. Wiley, New York

Baker T, Nelson RE (2005) Creating something from nothing: resource construction through entrepreneurial bricolage. Adm Sci Q 50:329-366

Beckert J, Bronk R (2018) An introduction to uncertain futures. In: Beckert J, Bronk R (eds) Uncertain futures. Oxford University Press, Oxford, pp 1-36

Bhowmick S (2011) Effectuation and the dialectic of control. Small Enterp Res 18:51-62

Bhowmick S (2015) They look while they leap: Generative co-occurrence of enactment and effectuation in entrepreneurial action. J Manag Organ 21:515-534

Busenitz LW, Barney JB (1997) Differences between entrepreneurs and managers in large organizations: Biases and heuristics in strategic decision-making. J Bus Ventur 12:9-30

Chandler GN, DeTienne DR, McKelvie A, Mumford TV (2011) Causation and effectuation processes: a validation study. J Bus Ventur 26:375-390

Chwolka A, Raith MG (2012) The value of business planning before start-up — a decision-theoretical perspective. J Bus Ventur 27:385-399

Corbett AC (2007) Learning asymmetries and the discovery of entrepreneurial opportunities. J Bus Ventur 22:97-118

De Bettignies JE, Brander JA (2007) Financing entrepreneurship: bank finance versus venture capital. J Bus Ventur 22:808-832

DeTienne DR, McKelvie A, Chandler GN (2015) Making sense of entrepreneurial exit strategies: a typology and test. J Bus Ventur 30:255-272

Dew N, Sarasvathy SD (2002) What effectuation is not: further development of an alternative to rational choice. Paper presented at the Annual Meeting of the Academy of Management, Denver, CO

Dew N, Read S, Sarasvathy SD, Wiltbank R (2008) Outlines of a behavioral theory of the entrepreneurial firm. J Econ Behav Organ 66:37-59

Dew N, Read S, Sarasvathy SD, Wiltbank R (2009) Effectual versus predictive logics in entrepreneurial decision-making: Differences between experts and novices. J Bus Ventur 24:287-309

Dougherty D, Heller T (1994) The illegitimacy of successful product innovation in established firms. Organ Sci 5:200-218

Ferreira JJ, Fernandes CI, Kraus S (2019) Entrepreneurship research: mapping intellectual structures and research trends. Rev Manag Sci 13:181-205

Fisher G (2012) Effectuation, causation, and bricolage: a behavioral comparison of emerging theories in entrepreneurship research. Entrep Theory Pract 36:1019-1051

Forlani D, Mullins JW (2000) Perceived risks and choices in entrepreneurs' new venture decisions. J Bus Ventur 15:305-322

Foss NJ, Klein PG (2012) Organizing entrepreneurial judgment. Cambridge University Press, Cambridge

Gigerenzer G (2008) Why heuristics work. Perspect Psychol Sci 3:20-29

Gigerenzer G, Gaissmaier W (2011) Heuristic decision making. Annu Rev Psychol 62:451-482

Grégoire DA, Cherchem N (2020) A structured literature review and suggestions for future effectuation research. Small Bus Econ 54:621-639

Gruber M (2007) Uncovering the value of planning in new venture creation: a process and contingency perspective. J Bus Ventur 22:782-807

Hansson SO (1994) Decision theory. Royal Institute of Technology, Stockholm

Herbener JM (1992) The role of entrepreneurship in desocialization. Rev Austrian Econ 6:79-93

Hofstede G (1980) Culture's consequences: international differences in work-related values. Sage Publications, Beverly Hills

Hsu DH (2004) What do entrepreneurs pay for venture capital affiliation? J Finance 59:1805-1844 
Jiang Y, Tornikoski ET (2019) Perceived uncertainty and behavioral logic: temporality and unanticipated consequences in the new venture creation process. J Bus Ventur 34:23-40

Kahneman D, Tversky A (1979) Prospect theory: an analysis of decision under risk. Econometrica 47:263-291

Karhu P, Ritala P (2020) The multiple faces of tension: dualities in decision-making. RMS 14:485-518

Kim PH (2015) Action and process, vision and values. In: Baker T, Welter F (eds) The Routledge companion to entrepreneurship. Routledge, New York, pp 59-74

Kirzner I (1973) Competition and entrepreneurship. University of Chicago Press, Chicago

Klein PG (1999) Entrepreneurship and corporate governance. Q J Austrian Econ 2:19-42

Klein PG (2008) Opportunity discovery, entrepreneurial action, and economic organization. Strateg Entrep J 2:175-190

Klein PG, Klein SK (2001) Do entrepreneurs make predictable mistakes? evidence from corporate divestitures. Q J Austrian Econ 4:3-23

Knight FH (1921) Risk, uncertainty, and profit. Houghton Mifflin Co, Boston

Landström H (1998) Informal investors as entrepreneurs: decision-making criteria used by informal investors in their assessment of new investment proposals. Technovation 18:321-333

Langlois RN (1982) Subjective probability and subjective economics. New York University, New York

Lévesque M, Shepherd DA (2004) Entrepreneurs' choice of entry strategy in emerging and developed markets. J Bus Ventur 19:29-54

Lévi-Strauss C (1967) The savage mind. University of Chicago Press, Chicago

Mas-Tur A, Kraus S, Brandtner M, Ewert R, Kürsten W (2020) Advances in management research: a bibliometric overview of the review of managerial science. Rev Manag Sci (in press)

McKelvie A, Haynie JM, Gustavsson V (2011) Unpacking the uncertainty construct: Implications for entrepreneurship action. J Bus Ventur 26:273-292

McMullen JS (2015) Entrepreneurial judgment as empathic accuracy: a sequential decision-making approach to entrepreneurial action. J Inst Econ 11:651-681

McMullen JS, Dimov D (2013) Time and the entrepreneurial journey: the problems and promise of studying entrepreneurship as a process. J Manag Stud 50:1481-1512

Miller KD (2007) Risk and rationality in entrepreneurial processes. Strategic Entrep J 1:57-74

Milliken FJ (1987) Three types of perceived uncertainty about the environment: state, effect, and response uncertainty. Acad Manag Rev 12:133-143

von Mises L (1949) Human action. Yale University Press, New Haven

Mitchell JR, Shepherd DA (2012) Capability development and decision incongruence in strategic opportunity pursuit. Strateg Entrep J 6:355-381

von Neumann J, Morgenstern O (1944) Theory of games and economic behavior. Princeton University Press, Princeton

Newell A (1969) Heuristic programming: Ill-structured problems. In: Aronofsky J (ed) Progress in operations research, vol 3. Wiley, New York, pp 360-414

Packard MD, Clark BB, Klein PG (2017) Uncertainty types and transitions in the entrepreneurial process. Organ Sci 28:840-856

Pies I, Schreck P, Homann K (2019) Single-objective versus multi-objective theories of the firm: using a constitutional perspective to resolve an old debate. Rev Manag Sci (in press)

Rae D, Carswell M (2000) Using a life-story approach in researching entrepreneurial learning: the development of a conceptual model and its implications in the design of learning experiences. Educ Train 42:220-228

Read S, Sarasvathy S (2005) Knowing what to do and doing what you know: effectuation as a form of entrepreneurial expertise. J Private Equity 9:45-62

Read S, Song M, Smit W (2009) A meta-analytic review of effectuation and venture performance. J Bus Ventur 24:573-587

Reitman WR (1964) Heuristic decision procedures, open constraints, and the structure of ill-defined problems. In: Shelley MW, Bryan GL (eds) Human judgments and optimality. Wiley, New York, pp 282-315

Ribeiro-Soriano D, Kraus S (2018) An overview of entrepreneurship, innovation and sensemaking for improving decisions. Group Decis Negot 27:313-320

Rothbard MN (1962) Man, Economy, and State. D. Van Nostrand Company with the William Volker Fund, Princeton

Salerno JT (2008) The entrepreneur: real and imagined. Q J Austrian Econ 11:188-207 
Sarasvathy SD (2001) Causation and effectuation: toward a theoretical shift from economic inevitability to entrepreneurial contingency. Acad Manag Rev 26:243-263

Sarasvathy SD (2008) Effectuation. Elements of entrepreneurial expertise. Edward Elgar, Cheltenham

Savage LJ (1954) Foundations of statistics. Wiley, Oxford

Schneider P (2018) Managerial challenges of Industry 4.0: an empirically backed research agenda for a nascent field. Rev Manag Sci 12:803-848

Semrau T, Ambos TC, Kraus S (2016) Entrepreneurial orientation and SME performance across societal cultures. J Bus Res 69:1928-1932

Shane S, Delmar F (2004) Planning for the market: business planning before marketing and the continuation of organizing efforts. J Bus Ventur 19:767-785

Shepherd DA, Williams TA, Patzelt H (2015) Thinking about entrepreneurial decision making: review and research agenda. J Manag 41:11-46

Shirokova G, Osiyevskyy O, Laskovaia A, MahdaviMazdeh H (2020) Navigating the emerging market context: performance implications of effectuation and causation for small and medium enterprises during adverse economic conditions in Russia. Strateg Entrep J (in press)

Simon HA (1973) The structure of ill structured problems. Artif Intell 4:181-201

Simon HA (1976) Administrative bhavior, 4th edn. The Free Press, New York

Simon HA, Newell A (1958) Heuristic problem solving: the next advance in operations research. Oper Res 6(1):1-10

Steenkamp JBEM, ter Hofstede F, Wedel M (1999) A cross-national investigation into the individual and national cultural antecedents of consumer innovativeness. J Mark 63:55-69

Stone B (2013) The everything store, Jeff Bezos and the age of Amazon. Black Bay Books, New York

Townsend DM, Busenitz LW, Arthurs JD (2010) To start or not to start: outcome and ability expectations in the decision to start a new venture. J Bus Ventur 25:192-202

Townsend DM, Hunt RA, McMullen JS, Sarasvathy SD (2018) Uncertainty, knowledge problems, and entrepreneurial action. Acad Manag Ann 12:659-687

Tumidei D, Alexiou C, Bourne M (2020) A choice and inevitability framework in strategic management: empirical evidence of its real-life existence. Rev Manag Sci (in press)

Weick KE (1979) The social psychology of organizing. McGraw-Hill, New York

Weick KE (1995) Sensemaking in organizations. Sage Publications, Thousand Oaks

Weick KE, Sutcliffe KM, Obstfeld D (2005) Organizing and the process of sensemaking. Organ Sci 16:409-421

Welter C, Kim S (2017) Effectuation under risk and uncertainty: a simulation model. J Bus Ventur 33:100-116

Welter C, Mauer R, Wuebker RJ (2016) Bridging behavioral models and theoretical concepts: effectuation and bricolage in the opportunity creation framework. Strateg Entrep J 10:5-20

Wilson CZ, Alexis M (1962) Basic frameworks for decisions. J Acad Manag 5:150-164

Wiltbank R, Read S, Dew N, Sarasvathy SD (2009) Prediction and control under uncertainty: outcomes in angel investing. J Bus Ventur 24:116-133

Witte T (1979) Heuristisches Planen, Vorgehensweisen zur Strukturierung betrieblicher Planungsprobleme. Gabler, Wiesbaden

Wood MS, Williams DW (2014) Opportunity evaluation as rule-based decision making. J Manag Stud 51:573-602

Wood MS, Williams DW, Drover W (2017) Past as prologue: entrepreneurial inaction decisions and subsequent action judgments. J Bus Ventur 32:107-127

Wu B, Knott AM (2006) Entrepreneurial risk and market entry. Manag Sci 52:1315-1330

Zacharakis AL, Shepherd DA (2001) The nature of information and overconfidence on venture capitalists' decision making. J Bus Ventur 16:311-332

Publisher's Note Springer Nature remains neutral with regard to jurisdictional claims in published maps and institutional affiliations. 